\title{
O pecado do historiador: para uma leitura d'A Feiticeira, de Jules Michelet
}

\author{
Maria Juliana Gambogi Teixeira*
}

\section{RESUMO}

Desde sua publicação, em 1862, a recepção de $A$ Feiticeira foi marcada pela perplexidade diante da maneira como seu autor, Jules Michelet, integrou o mito à narrativa histórica. Esse procedimento, que inspirou uma fortuna crítica disposta a ler tal obra mais sob a ótica literária do que como trabalho de história, tende a distorcer os objetivos e propósitos visados pelo historiador. Este artigo visa apresentar uma interpretação para as heterodoxias narrativas de Michelet como o resultado de uma reflexão eminentemente historiográfica. Para isso, sustento que a compreensão do papel central do mito, tal como mobilizado em $A$ Feiticeira, apoia-se na constituição de um "método histórico", cujo estabelecimento e fundamentação são diretamente derivados da leitura e da tradução que Michelet propôs para a obra do filósofo napolitano Giambattista Vico, em particular, a Ciência nova.

Palavras-chave: Jules Michelet; A Feiticeira; Giambattista Vico; Ciência nova; mito.

\section{ABSTRACT}

Since its publication in 1862, the reception of The Sorceress has been marked by a bewilderment prompted by the way Jules Michelet employs the myth as a form of historical narrative. In fact, his procedure has inspired readings that consider the book a work of literature, rather than a History book. This is very misleading, for it distorts Michelet's own goals and methods. This paper presents an interpretation of Michelet's heterodox narratives as a historiographical work. I argue that, in order to understand the central role of mythological structures in the "historical method" developed in The Sorceress, one needs to pay attention to the fact that it is grounded on the work of Neapolitan philosopher Giambattista Vico, especially in Michelet's own translation of Scienza nuova.

Keywords: Jules Michelet; The Sorceress; Giambattista Vico; Scienza nuova; myth.

Artigo - DOI - http://dx.doi.org/10.1590/2237-101X014027010 
Em fins de outubro do ano de 1862, Jules Michelet, já entâo bastante conhecido, celebrado e atacado por sua obra historiográfica, publica um novo trabalho, intitulado La Sorcière. ${ }^{1}$ Retomando um tema já investigado em diversos títulos anteriores, esse livro recupera o fenômeno da feitiçaria, evocado diversas vezes na obra pregressa, tratando-o, agora, de forma mais concentrada. ${ }^{2}$

O resultado dessa concentração será uma improvável história da feitiçaria "moderna", vistos os procedimentos narrativos e estilísticos adotados em sua feitura. Ciente da excentricidade da narrativa que trazia a público, Michelet tenta se adiantar à crítica, ironizando em torno do "pecado do historiador". Assim se exprime:

Eis, agora, meu pecado, onde a crítica me espera. Nessa longa análise histórica e moral da criação da Feiticeira ${ }^{3}$ até 1300, ao invés de me arrastar em explicaçôes prolixas, eu tomei, frequentemente um pequeno fio biográfico e dramático, a vida de uma mesma mulher durante três séculos. - E isso (notem bem) em seis ou sete capítulos somente. — Nessa mesma parte, tão curta, sentir-se-á, tranquilamente, o quanto tudo é histórico e fundamentado. ${ }^{4}$

\footnotetext{
${ }^{1}$ As três ediçôes brasileiras da obra em questão apresentam problemas, maiores ou menores, que arrolaremos a seguir. A edição do Círculo do Livro, hoje disponível apenas em sebos, subtrai todo o capítulo "Notas e esclarecimentos", capítulo metodológico no qual o historiador arrola fontes e comenta os fundamentos de sua interpretação. Já a edição da Aquariana, disponível no mercado, traz apenas a primeira metade do livro, deixando de lado tanto a segunda metade quanto o capítulo metodológico. A única edição que não faz cortes na obra é a proposta pela Nova Fronteira (também esgotada), que, no entanto, transfere o capítulo metodológico do fim (como aparece no original) para o início do livro.

${ }^{2}$ Para uma análise mais detida acerca da concepção e da recepção de $A$ Feiticeira, ver VIALLANEIX, Paul. Préface. In: MICHELET, Jules. La Sorcière. Paris: GF-Flammarion, 1966. p. 15-24; PETITIER, Paule (Org.). La Sorcière de Jules Michelet — l'envers de l'histoire. Paris: Honoré Champion, 2004; MICHELET, Jules. La Sorcière. Nouvelle édition critique avec introduction, variantes, et examen du manuscrit, publié par Wouter Kusters. Nijemegen: Katholieke Universiteit, 1989.

${ }^{3}$ Há uma curiosa variação tipográfica da palavra "feiticeira" no corpo do texto em questão. Surgindo ora em maiúscula, ora em minúscula, essa mobilidade tipográfica, porque proposta por um autor bastante cuidadoso com a preparação de seus originais, não merece ser desprezada. Com efeito, um padrão gráfico parece se depreender dessa variabilidade, indiciando que o substantivo em maiúscula (Feiticeira) refere-se, prioritariamente, à personagem que ocupa a primeira metade do livro, ao passo que o mesmo termo, em minúscula (feiticeira), remete ao período de popularização do fenômeno, temática da segunda parte da obra. Uma vez que este texto cuida de entender principalmente essa primeira metade, optamos por seguir exatamente o procedimento de Michelet, grafando o termo em maiúscula, tanto nas referências ao título do livro, quanto nos momentos em que nomeamos sua personagem principal.

4 "Maintenant, voici mon péché ou mattend la critique. Dans cette longue analyse historique et morale de la création de La Sorcière jusqu'en 1300, plutôt que de traîner dans les explications prolixes, j’ai pris souvent un petit fil biographique et dramatique, la vie d'une même femme pendant trois cents ans. - Et cela (notez bien) dans six ou sept chapitres seulement. - Dans cette partie même, si courte, on sentira aisément combien tout est historique et fondé.” MICHELET, Jules. La Sorcière, op. cit. p. 296. Salvo menção oposta, esta e todas as outras traduções repertoriadas neste artigo são de minha inteira responsabilidade.
} 
Talvez não seja abusivo dizer que "essa parte" nem é tão curta, conformando, na verdade, toda a primeira metade do livro, dominada pela dicção lendária, nem, consequentemente, é tão simples quanto queria fazer crer o historiador. Ao contrário, pretender historiográfica uma narrativa na qual uma das personagens arroladas "vive" trezentos anos, pare e esposa Satã desafia, num primeiro momento, não apenas o campo da ciência mas os limites do bom senso. Assim, se é fácil reconhecer no enredo de La Sorcière traços evidentes do ficcional, mais complicado é compreender como esse historiador pretendeu ser tudo isso "histórico e fundamentado".

O mais das vezes, a recepção crítica do livro respondeu ao problema a partir de duas chaves que, embora possam ser complementares, nem sempre se sobrepóem. De um lado, a chave da "historiografia romântica", etiqueta imprecisa, mas que costuma responder, nesse caso, por uma suposta ignorância ou ingenuidade quanto às diferenças entre a escrita do fato e da ficção. 5 De outro lado, há os que invertem aquela leitura negativa do problema, substituindo a ignorância pela vontade deliberada de construir uma narrativa que pertence, ao mesmo tempo, a ambos os domínios, ao abraçar a economia do mito como modelo de representação. ${ }^{6}$ De ambos os lados, a obra de Michelet se divisa sob o signo de uma história que cede o passo à ficçáo.

Um terceiro caminho interpretativo seria o de tentar compreender as razóes pelas quais o historiador, optando conscientemente por procedimentos "de tipo literário", ainda assim defendeu esse título como "o mais inatacável da obra", afirmando que tais procedimentos não o aproximam, mas, antes, o afastam da "imaginação, [de] uma vã poesia pueril". 7 Esse será o caminho deste texto.

Fundamentar a narrativa de La Sorcière, depreender um fio narrativo a partir de uma trama construída tanto pelo escrutínio e exposição sistemática de suas fontes primárias e secundárias quanto pelo recurso a uma base factual que delimite a geografia e a periodização da feitiçaria é trabalho ao qual Michelet não se furtou. Cioso de seu posto de historiador e

\footnotetext{
${ }^{5}$ Essa chave, de extração historiográfica e, sobretudo, francesa, é visada criticamente por Marcel Gauchet em seu livro Philosophie des sciences historiques. Le moment romantique (Paris: Editions du Seuil, 2002), e cujo argumento adoto aqui. Sem qualquer pretensáo exaustiva, repertoriamos, a seguir, alguns artigos exemplares dessa matriz de recepção: ARIÈS, Philippe. A história "científica". In: ARIÈS, Philippe. O tempo da história. Rio de Janeiro: Francisco Alves, 1989. p. 208-231; LE GOFF, Jacques. Pour une autre Moyen Âge. Paris: Gallimard, 1977; NORA, Pierre. Le troisième homme. L'Arc, Paris, n. 53, p. 48-58, 1972.

${ }^{6}$ A matriz principal dessa leitura se encontra na recepção micheletiana de Roland Barthes, muito particularmente no artigo: BARTHES, Roland. La Sorcière. In: BARTHES, Roland. Oeuvres complètes. Paris: Seuil, 1993. t. I, p. 1250-1259.

${ }^{7}$ Ambas as citaçóes se encontram em La Sorcière, a primeira no "Avis de la seconde édition"; a segunda no capítulo metodológico, intitulado "Notes et éclaircissements".
} 
possivelmente escaldado com o mote contínuo de que seus textos valeriam mais para o deleite da imaginação do que por seus dotes analíticos, ${ }^{8}$ ele parecia especialmente preocupado em legitimar essa narrativa, exibindo cuidadosamente o percurso historiográfico que embasava sua composição. Uma profusão de notas de pé de página - mais numerosas do que de costume - , lista bibliográfica ao fim do volume e, sobretudo, um capítulo metodológico — "Notas e esclarecimentos" — , tido pelo autor como o mais importante da obra e atento a justificar cada detalhe, especialmente os que concerniam àquele pequeno fio biográfico e dramático. O que talvez ajude a explicar o porquê de a maioria das hipóteses desse livro ver-se repercutida em publicaçóes contemporâneas sobre o tema, as quais, de ordinário, não têm La Sorcière como fonte bibliográfica.?

Essas semelhanças tenderiam a confirmar a pretensão à referencialidade, sustentada pelo historiador. Náo se trata, porém, de associar o conceito de real mobilizado por Michelet nessa narrativa à maneira como a historiografia contemporânea costuma encarar o problema. Ao invés disso, trata-se de reconhecer que a historiografia micheletiana, embora partindo de pressupostos estranhos à maneira como a ciência histórica moderna se constituiu, também se institui a partir de um recorte de pretensão científica e igualmente separa o que pode a literatura do que deve a história.

"Eu nasci de Vico", afirma Michelet, dois anos antes de sua morte, 45 depois de ter publicado uma tradução da Ciência nova, fundamental para a divulgação da obra do filósofo na Europa oitocentista. ${ }^{10}$ Embora jamais adotando uma postura de discípulo, Michelet sempre deixou evidente, ao longo de toda a obra, sua dívida intelectual com o pensamento de

\footnotetext{
${ }^{8}$ A recepção "literária" da obra de Michelet é contemporânea ao historiador e foi um problema que ele não cessou de enfrentar e combater ao longo de toda a obra. No geral, seus prefácios constituem o espaço privilegiado para esse tipo de debate, também registrados em seus diários e sua correspondência. A título de exemplo, que se relembre sua carta a Taine, em resposta a uma resenha do crítico tratando de sua História da França no século XVI. Nessa carta, em tom de duvidosa cordialidade, Michelet lhe responde afirmando que "sendo novo na crítica, ignorais ainda que esse nome de poeta que me outorgais é justamente a acusaçáo sob a qual se acreditou até agora espezinhar o historiador. Essa palavra respondeu a tudo". A carta foi publicada, entre outros, em BARTHES, Roland. Michelet. São Paulo: Companhia das Letras, 1991. p. 84.

${ }^{9}$ Elementos cronológicos e interpretativos de La Sorcière parecem encontrar eco em publicaçóes da historiografia contemporânea sobre o assunto. A título de exemplo, destaco apenas um tópico, dos muitos que podem ser elencados: os trezentos anos de vida de sua feiticeira original remetem, segundo o corpo e as notas do texto, aos séculos XII e XIV. Longe de ser arbitrária, a cronologia dessa história encontra apoio e endosso em alguns estudiosos. Sem qualquer pretensão à exaustividade, podemos citar História do medo no Ocidente (São Paulo: Companhia das Letras, 1996), de Jean Delumeau, para quem essas datas demarcam um percurso histórico de progressão do medo cujas características ajudam a compreender não poucos traços delineados por Michelet em La Sorcière. Destacamos, ainda, GINZBURG, Carlo. História noturna: decifrando o sabá. São Paulo: Companhia das Letras, 1991; Jean Chelini, em particular os capítulos "Ruptures et refus de l'unité, les instruments nouveaux de l'unité" e "Les temps des schismes". In: CHELINI, Jean. Histoire religieuse de l'occident medieval. Paris: Hachette, 1991 e, ainda, GAUVARD, Claude; DE LIBERA, Alain; ZINK, Michel. Dictionnaire du Moyen Age. Paris: PUF, 2002.

${ }^{10}$ Citado em VIALLANEIX, Paul. Introduction. In: MICHELET, Jules. Euvres complètes. Paris: Flammarion, 1971. t. I, p. 275.
} 
Giambattista Vico. Com efeito, é possível sustentar diversos e contínuos pontos de contato entre aquele corpus filosófico e a carreira historiadora que nascerá logo após essa tradução, desde que não se perca de vista o caráter fortemente heterodoxo que, logo de início, marcou a abordagem de Vico por Michelet. Em outros termos, menos do que uma historiografia viconiana, o que a obra do historiador oferece é uma reflexão sobre o passado inspirada por um corpus filosófico heterodoxamente reinterpretado e historiograficamente reinventado, a saber, um Vico micheletiano. ${ }^{11}$

Esse Vico micheletiano é fundamental para a desmontagem do paradoxo constituído pela junção do "pequeno fio biográfico e dramático" "completamente histórico e fundamentado". Antes, porém, de avançar nessa direção, é preciso ter claro que nem o fio biográfico e dramático esgota as questôes propostas por essa história assim como tampouco ele se esgota no paralelo com a ciência viconiana. Ou seja, La Sorcière, tanto quanto Princípios da filosofia da história (título que Michelet propôs para a sua versão da Ciência nova) são infinitamente mais ricos e independentes entre si do que o cotejo aqui proposto deixará ver. Isso posto, a opção por restringir esta análise apenas ao recurso à dicção lendária, dominante na primeira metade de La Sorcière, e explorá-la em sua interface com elementos teóricos oriundos da leitura micheletiana de Vico visa, sobretudo, ensaiar um caminho de leitura que não ignore as condiçôes intelectuais próprias à fatura historiográfica micheletiana.

Se se pode afirmar que o "método" historiográfico micheletiano parte da filosofia de Vico, esse gênero de aproximação conduz não apenas a uma base conceitual que informa seus princípios interpretativos, mas também a uma apreensão do factual bastante específica. De fato, é na tentativa de associar criticamente, num mesmo projeto de conhecimento, o saber verdadeiro da filosofia e as certezas advindas da filologia que Vico empreende a construção de sua ciência. ${ }^{12}$

\footnotetext{
${ }^{11}$ Acerca da maneira como Michelet releu Vico, ver, em particular: REMAUD, Olivier. Michelet — la magistrature de l'histoire. Paris: Michalon, 1998; REMAUD, Olivier. Les archives de l'humanité: essai sur la philosophie de Vico. Paris: Seuil, 2004; CRISTOFOLINI, Paolo. Vico et l'histoire. Paris: PUF, 1995.

12 "A filosofia contempla a razão, de onde vem a ciência do verdadeiro; a filologia estuda os atos da liberdade humana, ela segue a autoridade; e é daí que vem a consciência do certo. - Assim, nós compreendemos sob o nome de filólogos todos os gramáticos, historiadores, críticos que se ocupam do conhecimento das línguas e dos fatos (tanto fatos interiores da história dos povos, como leis e costumes, quanto fatos exteriores, como guerras, tratados de paz e de aliança, comércio e viagens).

Esse mesmo axioma mostra-nos que os filósofos ficaram a meio caminho ao negligenciarem dar a seus raciocínios uma certeza tirada da autoridade dos filólogos; que os filólogos cometeram o mesmo erro, pois não deram aos fatos esse caráter de verdade que poderiam ter tirado dos raciocínios filosóficos. Se os filósofos e os filólogos tivessem evitado essa dupla armadilha, teriam sido mais úteis à sociedade e nos teriam poupado a pesquisa dessa nova ciência." VICO, Giambattista. Principes de la philosophie de l'histoire. In: MICHELET, Jules. Euvres complètes, op. cit. t. I, p. 433.
} 
Essa ciência, por seu turno, visaria extrair, do cotejo sistemático de dados filológicos e filosóficos, princípios capazes de responder pela lógica e pela inteligibilidade do mundo humano:

Na infinita variedade de ações, pensamentos, costumes e línguas que se nos apresenta a história do homem, frequentemente reencontramos os mesmos traços, as mesmas características. As nações mais distantes no tempo e no espaço seguem em suas revoluçóes políticas e em suas revoluçôes linguísticas uma marcha singularmente análoga. Distinguir os fenômenos regulares dos acidentais e determinar as leis gerais que regem os primeiros; traçar a história universal, eterna, que se produz no tempo sob a forma de histórias particulares, descrever o círculo ideal no qual gira o mundo real: eis o objetivo da nova ciência. Ela é, ao mesmo tempo, filosofia e história da humanidade. ${ }^{13}$

Assim, conquanto essa matriz filosófica, coerente com sua inscrição como corpus de ciência, vise não o estabelecimento de uma hermenêutica do particular, mas, antes, a dedução dos fundamentos mesmos do saber, isso não impede que a Ciência nova, paralelo às dignidades que irão acompanhar o princípio segundo o qual o mundo civil é obra dos homens, estabeleça um método exegético próprio para a leitura crítica dos “monumentos" que testemunham sobre a origem das civilizaçóes pagãs. Em face da dominância das formas poéticas nos testemunhos mais antigos da civilização, Vico propóe um entendimento da poesia que "se refere não à arte de exprimir-se em versos, mas à forma de sabedoria característica dos começos da humanidade"; ${ }^{14}$ ou seja, como o primeiro sistema de inteligibilidade e expressão na vida dos povos, modo e meio através do qual os primeiros homens começaram a constituir sua humanidade.

Lembremos primeiro deste axioma: Os homens são naturalmente conduzidos a consagrar a lembrança das leis e das instituiçôes que estão na base das sociedades às quais pertencem. - 2. A história nasceu primeiro, em seguida veio a poesia. Com efeito, a história é a simples enunciação do verdadeiro, do qual a poesia é uma imitação exagerada. (...) - 3. Como os poetas certamente precederam os historiadores vulgares, a primeira história deveu ser poética. - 4. As fábulas foram, na origem, narrativas verdadeiras e de caráter sério, e muthos, fábula, foi definido como

\footnotetext{
13 "Dans cette variété infinie d'actions et de pensées, de mours et de langues que nous présente l'histoire de l'homme, nous retrouvons souvent les mêmes traits, les mêmes caractères. Les nations les plus éloignées par les temps et par les lieux suivent dans les révolutions politiques, dans celles du langage, une marche singulièrement analogue. Dégager les phénomènes réguliers des accidentels, et déterminer les lois générales qui régissent les premiers; tracer l'histoire universelle, éternelle, qui se produit dans le temps sous la forme des histoires particulières, décrire le cercle idéal dans lequel tourne le monde réel: voilà l'objet de la nouvelle science. Elle est tout à la fois la philosophie et l'histoire de l'humanité." MICHELET, Jules. Discours sur Vico. In: MICHELET, Jules. Euvres complètes, op. cit. t. I, p. 288.

${ }^{14}$ LACERDA, Sônia. Metamorfoses de Homero. Brasília: Editora Universidade de Brasília, 2003. p. 243.
} 
vera narratio. (..) - 6. Os caracteres poéticos, que são a essência das fábulas, nasceram de uma impotência natural dos primeiros homens, incapazes de, diante de um objeto, abstrair suas formas e propriedades; consequentemente, esses caracteres revelam uma maneira de pensar comandada pela natureza a naçôes inteiras, na época de sua barbárie mais profunda. ${ }^{15}$ (itálicos do autor)

Se a história nasceu primeiro, fruto natural da disposição humana em preservar, pela memória, a fundação do corpo social ao qual pertence, o modo como a "história ideal" de Vico estrutura uma história das ideias reconhece no poeta o historiador das idades primevas, na fábula a sua narrativa "verdadeira" e na poesia o seu lógos próprio (entendido, seguindo Vico, em sua dupla acepção de língua e pensamento). Lição exemplarmente bem compreendida em La Sorcière. Com efeito, o desenho de uma Idade Média imersa numa ordem lendária é, evidentemente, uma adesão explícita à noção de ricorso viconiana, ${ }^{16}$ adesão essa que, desde o início da obra historiográfica de Michelet, distingue seu modo de apreensão do período.

Uma coisa, é verdade, prometia a paz que renova: todas as escolas tinham se acabado, a via lógica abandonada. Um método infinitamente simples dispensava o raciocínio, abria a todos uma ladeira fácil, bastando descê-la. Se o credo era obscuro, a vida toda já estava traçada nos caminhos da lenda. ${ }^{17}$

Ao constatar a presença do lendário como parte fundadora dessa ordem de mundo, o corolário mais imediato é o de apresentar essa "lógica” poética como modelo de pensamento/

15 "Rappelons d'abord cet axiome: Les hommes sont portes naturellement à consacrer le souvenir des lois et institutions qui font la base des sociétés auxquelles ils appartiennent. - 2. L'histoire naquit d'abord, ensuite la poésie. En effet, l'histoire est la simple énonciation du vrai, dont la poésie est une imitation exagérée. (...) 3. Les poètes ayant certainement précédé les historiens vulgaires, la première histoire dut être la poétique. — 4. Les fables furent à leur origine des récits véritables et d'un caractère sérieux, et mythos, fable, a été défini par vera narratio. (...) - 6. Les caracteres poétiques, qui sont l'essence des fables, naquirent d'une impuissance naturelle des premiers hommes, incapables d'abstraire du sujet ses formes et ses propriétés; en conséquence, nous trouvons dans ces caractères une manière de penser commandée par la nature aux nations entières, à l'époque de leur plus profonde barbarie." VICO, Giambattista. Principes de la philosophie de l'histoire, op. cit. p. 540.

${ }^{16}$ Parece-nos justo dizer que a configuraçáo inicial do medievo no pensamento micheletiano é extremamente devedora das observações feitas por Vico sobre o período. Se, como afirma Remaud, Michelet não desconfigura os fundamentos da "história ideal eterna", a noção de corso, implícita nessa dinâmica, também deve ter sido bem compreendida por Michelet. Se isto é fato, cabe notar que, com Vico (e possivelmente com Michelet), o corso não se confunde com a descrição histórica e repetitiva de eventos particulares, mas remete à ideia de um quadro epistemológico, "um simples mecanismo sem qualquer ideia explícita de progresso e cujas etapas são expostas por Vico de maneira neutra”. GIRARD, Pierre. Le vocabulaire de Vico. Paris: Ellipses, 2001. p. 10.

17 "Une chose promettait, il est vrai, la paix qui renouvelle: toutes les écoles étaient finies, la voie logique abandonnée. Une méthode infiniment simple dispensait du raisonnement, donnait à tous la pente aisée qu'il ne fallait plus que descendre. Si le credo était obscur, la vie était toute tracée dans le sentier de la légende." MICHELET, Jules. La Sorcière, op. cit. p. 53. 
expressão e ação de seus atores, determinando assim, para o historiador interessado em bem compreender o período, a recepçáo desse tipo de fonte como o registro por excelência da empresa historiográfica. Ou seja, o privilégio que Michelet confere a esse gênero de documento e, mais amplamente, a forma como opera com esse tipo de material, de sabor "literário", atribuindo-lhe um valor ativo e concreto sobre a ordem social que o fabrica, náo é, de modo algum, uma eleição por gosto, veleidade de um narrador querendo decorar sua história com o poder encantatório das palavras poéticas. Ou seja, a aproximação, aqui, não se dá por identificaçáo entre o narrador e a cena narrativa - que, ao contrário, sabe se tratarem de "sonhos estranhos, ricos em milagres, loucuras absurdas e sedutoras"18 —, mas surge como precondição particular ao conhecimento histórico dessa época.

Bem representativo, nesse caso, é a forma como retoma a formação da "Vida dos Santos":

Ela tem sua raiz profunda no solo; o povo a semeia e a família a cultiva, todos participam de sua confecção, os homens, as mulheres, as crianças. A vida precária e inquieta desses tempos de violência tornava essas pobres tribos imaginativas, crédulas em seus próprios sonhos que as tranquilizavam (...) Vox populi, vox Dei! Mas onde acharam essa história? Eles apresentavam testemunhos verídicos, irrecusáveis: a árvore, a pedra, que viram a aparição, o milagre. ${ }^{19}$

"O que dizer diante disso?" - prossegue o historiador, evidentemente acossado pela natureza irredutivelmente estranha desse universo no qual adentra. Nada, senão, num primeiro instante, reter o gesto primordial que permitiu a essas histórias escaparem do esquecimento, conservando, malgrado as agruras que lhes impingiram os homens ao longo do tempo, um resto de dimensão testemunhal.

Levada para a abadia, a lenda encontrará um monge, bom para nada, que só sabe escrever, que é curioso, acredita em tudo, em todas as coisas maravilhosas. Ele escreve essa daqui, borda-a com sua retórica superficial, estraga-a um pouco. Mas ei-la então consignada e consagrada, lida no refeitório, logo na igreja. Copiada, ornamentada, sobrecarregada de adereços muitas vezes grotescos, ela prossegue, de século em século, até que tome seu honroso lugar no fim das Lendas áureas. ${ }^{20}$

\footnotetext{
${ }^{18}$ MICHELET, Jules. La Sorcière, op. cit. p. 54.

19 "Elle a sa racine profonde dans le sol; le peuple l'y sème, et la famille l'y cultive, et tous y mettent la main, les hommes, les femmes et les enfants. La vie précaire, inquiète, de ces temps de violence, rendait ces pauvres tribus imaginatives, crédules pour leurs propres rêves, qui les rassuraient. (...) Vox populi, vox Dei!' (...) Mais comment l'ont-ils trouvée? On lui montrait des témoins véridiques, irrécusables: l'arbre, la pierre, qui ont vu l'apparition, le miracle." Ibid., p. 54.

20 "Rapportée à l'abbaye, la légende trouvera un moine, propre à rien, qui ne sait qu'écrire, qui est curieux, qui croit tout, toutes les choses merveilleuses. Il écrit celle-ci, la brode de sa plate rhétorique, gâte un peu. Mais la voici consignée et consacrée, qui se lit au réfectoire, bientôt à l'église. Copiée, chargée, surchargée d'ornements souvent grotesques, elle ira de siècle en siècle, jusqu'à ce que honorablement elle prenne rang à la fin dans la Légende dorée." Ibid., p. 55.
} 
Essa consignação inicial é condição sine qua non para que "se leia, ainda hoje, essas belas histórias", completa o historiador. Por outro lado, a consignação, apenas, não basta. Não se trata de, como o monge, acreditar em "todas as coisas maravilhosas". Ao contrário, cabe ao historiador ser capaz de, por meio de um método crítico, distinguir o que é "ornamento", "adereço" do que é "testemunho verídico". Nesse caso, o primeiro passo depende do manejo de uma crítica filológica capaz de assinalar e interpretar os testemunhos que se ligam de forma necessária ao período. Desafio de impacto. Conforme indica o historiador, à medida que a cronologia remonta aos seus períodos mais arcaicos, a documentação faz-se esparsa e rara: "os textos antigos são raros e os que encontramos esparsos nos livros bastardos de 1500 e 1600 são difíceis de distinguir" ${ }^{21}$ Dificuldade devida năo apenas à usura própria ao tempo ou à censura deliberada dos poderes constituídos, mas, e em especial, à propensão, típica de períodos posteriores, em constituir um corpus propriamente literário ou legendário do que antes não passava de uma forma natural de interação e interpretação do mundo, instituída e instituindo a inteligência e a fé, a lógica e as leis de um outro mundo, ou seja, "suas belas histórias".

Assim, tanto a precariedade das fontes quanto a precariedade dos meios através dos quais essas fontes chegam até o presente obrigam o historiador a um trabalho árduo. E o principal desafio a ser superado implica o reconhecimento das "línguas da história", ou seja, do modo distinto através do qual os homens, ao longo do tempo, experimentaram, compreenderam e, finalmente, registraram sua aventura na terra. Em boa medida, essa historicização do lógos, revertido em línguas históricas, pode ser compreendida como parte intrínseca do edifício viconiano, pois ele não apenas supóe a excelência e mesmo a prevalência desse objeto como testemunho primordial das coisas, mas também parece tomar a "res linguística" como o ponto de interseção entre o mundo das ideias e o dos fenômenos. ${ }^{22}$

À medida que a língua não pode ser separada do regime temporal no qual se forma, o filólogo postula que cada documento contém os meios de contradizer as interpretaçóes que o tornariam anacrônicos. A verdade do texto torna-se index sui. A língua e sua história contextual são as únicas a poder fornecer os critérios de verificação dos sentidos. O primeiro exercício da razão crítica é um exercício de leitura literal e comparativa que interrompe o ciclo de compreensáo

\footnotetext{
${ }^{21}$ Ibid., p. 295.

${ }^{22}$ Esse é o argumento principal de Jurgen Trabant, para quem uma das originalidades do pensamento viconiano está em seu modo de refletir sobre a linguagem, abolindo o hiato entre o mundo das coisas e o mundo das ideias, ao dispor a "res linguística" como meio - in mezzo — ou como laço de união entre ambas as instâncias. Diz o autor: "Vico dispóe a imaginação e a corporeidade como fundamentos primeiros da razão. (...) A interioridade do espírito é ultrapassada, então, pela linguagem — ou pela semiose — à medida que, através do signo, estabelece-se uma ligação sintética do dentro e do fora e, consequentemente, do interior ao exterior (...) no meio, 'in mezzo' da res cogitans e da res extensa, está a res linguistica”. Ver TRABANT, Jurgen. La sématologie de Vico. In: GIRARD, Pierre; REMAUD, Olivier. (Orgs.). Recherches sur la pensée de Vico. Paris: Ellipses, 2003. p. 54.
} 
deformante. $^{23}$

Tratar-se-ia, com Vico, de uma leitura "endoscópica”, “imanente” ao tecido linguístico que analisa, o que faz com que o repertório e a estrutura lendários, na chave viconiana acionada por Michelet, não sejam apenas um dos documentos disponíveis, mas se imponham como o modelo de inteligibilidade próprio a esse passado. Sua reconstituição exige que o intérprete se desprenda dos conceitos através dos quais seu tempo lhe informa o que vem a ser lenda, língua ou poesia, de modo a, corretamente, compreender sua mensagem.

Portanto, ante uma crítica pronta a denunciar o recurso ao lendário como pecado do historiador, Michelet talvez pudesse responder, na esteira de seu mestre, que o grande pecado para a inteligência do passado estaria em não reconhecer a existência e a prevalência das outras formas de expressão e de pensamento de que dispuseram os homens ao longo do tempo.

O pecado intelectualista, o que Vico chama de boria dei dotti, a "vã pretensão dos eruditos", consiste em projetar sobre um universo que não se estrutura a partir da razão as categorias de uma razão "plenamente desenvolvida", e cujo desenvolvimento só se dará ao termo de um longo processo histórico, cujas primeiras etapas são marcadas pela predominância dos sentidos e da imaginação. Vico polemiza, assim, tanto com aqueles que sustentaram que, nos tempos mais distantes, os homens ou alguns dentre eles teriam sido dotados de uma sabedoria 'escondida', dissimulada voluntariamente pelas formulações simbólicas quanto com aqueles que, em nome de uma "razão plenamente desenvolvida", consideram os mitos, os ritos e os costumes primitivos absurdos e sem significação. ${ }^{24}$

Pecado típico do intelectual, ou seja, de períodos em que as categorias abstratas já conformam um campo próprio à razão, a vaidade dos doutos é uma variante ilustrada do antropomorfismo característico daquela poesia das origens, o qual implica "só imaginar do objeto o que se pode imaginar de si” ${ }^{25}$ Rearticulada pelos sábios, especifica-se como uma das

\footnotetext{
23 "Dans la mesure où la langue n'est pas séparable du régime temporel dans lequel elle se forme, le philologue postule que chaque document contient les moyens de contredire les interprétations qui le rendent anachronique. La vérité du texte devient index sui. La langue et son histoire contextuelle sont les seules à pouvoir fournir les critères de la vérification du sens. La premier exercice de la raison critique est un exercice de lecture littérale et comparative qui interrompt le cycle des compréhensions déformantes." REMAUD, Olivier. Les archives de l'humanité. Paris: Seuil, 2004. p. 258.

24 'Le péché intellectualiste, ce que Vico appelle la boria dei dotti, la 'vaine prétention des érudits', consiste à projeter sur un univers qui ne relève pas de la raison les catégories d'une raison 'pleinement développée', qui ne s'épanouit chez l'homme qu'au terme d'un long processus historique dont les premières étapes sont marquées par la prédominance des sens et de l'imagination. Vico polémique donc aussi bien contre ceux qui voudraient que, dans les temps reculés, les hommes, ou certains d'entre eux, aient été doués d'une sagesse 'cachée', dissimulée volontairement derrière des formulations symboliques, que contre ceux qui, au nom de leur raison 'pleinement développée', traitent d'absurdités sans signification les mythes, rites et coutumes des primitifs." PONS, Alain. De la "nature commune des nations" au peuple romantique, note sur vico et Michelet. Romantisme, n. 9, p. 46, 1975.

${ }^{25}$ REMAUD, Olivier. Les archives de l'humanité. Paris: Seuil, 2004. p. 206.
} 
espécies de anacronismo descortinadas e combatidas por Vico, tão mais prejudicial quanto falseia não apenas uma época e os documentos que dela restaram, mas também as próprias categorias de pensamento pelas quais procede. Nesse sentido, a boria dei dotti estrutura-se mais como crença do que como um juízo crítico, e sua negatividade advém do fato de que, fantasiada como razão, comete o sério pecado de expropriar "o passado de seu ser (...), de seu caráter de passado". ${ }^{26}$

Por isso, a tarefa do historiador exige que este ponha continuamente à prova o seu próprio sistema de pensamento, sendo capaz de desgarrar-se até mesmo de suas premissas mais caras, a fim de dar conta das "leis necessárias que governam as próprias coisas, notadamente as coisas do passado". ${ }^{27}$

Portanto, ao menos parcialmente, a dicção lendária característica do livro 1 de La Sorcière justifica-se historicamente por meio de um método crítico de leitura e interpretação do Medievo que, retomado sob a chave do ricorso viconiano, desenha uma ordem de mundo de tipo "poético", "fabuloso". Dominante no corpo da narrativa, esse conteúdo vê-se, no entanto, a cada instante calçado pela exposição sistemática tanto das fontes documentais quanto dos elementos analíticos que permitiriam sua correta interpretação - como escrevera Michelet, "tudo histórico e bem fundamentado".

A adequação entre a cena narrativa e os elementos conceituais não deve, no entanto, obliterar o hiato entre o recurso a um modelo de interpretaçáo (como o de Vico) e seu uso como práxis de dramatizaçáo, desenvolvido, aqui, por Michelet. Pois, se garantir a inteligibilidade própria a um universo do poético significa reconhecer a existência de distintos modelos de veracidade - dentre os quais as ideias míticas aparecem como "verdadeiras na forma, conquanto falsas na matéria" —, isso não implica, necessariamente, dever copiá-la. ${ }^{28}$

O problema entấo se concretiza exatamente onde o via Michelet: naquele pequeno fio fictício que reconta a origem da Feiticeira a partir da biografia de uma mesma mulher ao longo de trezentos anos. É certo que nosso narrador não se furta em ancorar essa performatização biográfica numa estrutura contextual fortemente determinada: o pequeno fio ficcional reverbera continuamente os grandes lances da história. A exemplo da fisiologia e da psicologia do pequeno demônio do lar, os principais elementos dessa biografia se calçam em citaçôes eruditas:

Foi somente em 553 que a Igreja tomou a decisão atroz de danar os espíritos ou demônios (palavras sinônimas em grego), daná-los sem retorno e sem arrependimento possível. Seguiu, assim, a violência africana de Santo Agostinho, contra a opinião mais dócil dos gregos, de

\footnotetext{
${ }^{26}$ Ibid., p. 206.

${ }^{27}$ Ibid.

${ }^{28}$ Sobre os desvios interpretativos de Michelet no que toca à obra viconiana, ver, em particular, os artigos que Alain Pons dedicou ao tema.
} 
Orígenes e da Antiguidade. (Haag, Hist. dos dogmas, I, 80-83) — Desde então, os Espíritos são estudados, seus temperamentos são fixados, assim como sua fisiologia. Eles têm e não têm corpo, desaparecem na fumaça, mas adoram o calor, temem os golpes etc. Tudo é perfeitamente conhecido e convencionado em 1050 (Michel Psellus, Energia dos espiritos ou demônios). ${ }^{29}$

Portanto, conquanto travestido em narrador lendário, Michelet não deixa de buscar as evidências em função das quais pôde remedar não só o tom dessa voz poética, mas os objetos que ela consagra como existentes. Sob a ótica de Psellus, de sua personagem e dos 1200, o gênio do lar é um dado real, característico de um certo padrão de inteligibilidade típico a determinados períodos: "Ela julga como a criança. Tudo é humano, tudo é espírito". ${ }^{30} \mathrm{O}$ que, no entanto, não apaga o fato de que, como narrador e, sobretudo, no que toca à eleição da forma biográfica, também Michelet se comporta como se nela estivesse imerso.

Essa imersão, porém, é voluntariamente consciente e explicitamente anunciada: após os capítulos introdutórios que visam estabelecer "os dois grandes traços gerais, exteriores, da miséria da idade média, que fizeram com que ela se desse ao Diabo", o passo seguinte seria ver o "interior, o fundo dos costumes e sondar o dentro" ${ }^{31} \mathrm{E}$, com efeito, o que Michelet pretende discernir através dessa introspecção não é menos do que a questão crucial para essa narrativa, a saber, "como a mulher pode se tornar Feiticeira. Pesquisa delicada", ela impóe "o trabalho mais difícil", devido à ausência de precedentes. "Nenhum de meus predecessores se interrogou sobre isso. Não se informaram sobre os sucessivos graus através dos quais se chega a essa coisa horrível. Sua Feiticeira surge de repente, como que do fundo da terra. Tal não é a natureza humana". 32

Uma vez que esse é um tema para o qual seus predecessores não parecem ter atentado, o problema da origem da feitiçaria funciona como uma espécie de ponto cego dos estudos sobre a matéria e ponto de originalidade pretendido por essa obra historiográfica. A precariedade da documentação, nesse caso, é particularmente desafiadora. "Os textos antigos são raros e os que encontramos esparsos nos livros bastardos de 1500 e 1600 são de difícil distinção". ${ }^{33} \mathrm{O}$ que Michelet visa, então, não é exatamente a feitiçaria como fenômeno já assente, mas seus primeiros passos, suas primeiras ocorrências. Com efeito, a feiticeira lendária

\footnotetext{
29 "C'est seulement en 553 que l'Église a pris l'atroce résolution de damner les esprits ou démons (mots synonymes en grec), sans retour, sans repentir possible. Elle suivit en cela la violence africaine de saint Augustin, contre l'avis plus doux des Grecs, d'Origène et de l'antiquité (Haag, Hist. des dogmes, I, 80-83). - Dès lors on étudie, on fixe le tempérament, la physiologie des Esprits. Ils ont et ils n'ont pas de corps, s'évanouissent en fumée, mais aiment la chaleur, craignent les coups, etc. Tout est parfaitement connu, convenu, en 1050 (Michel Psellus, Energie des esprits ou démons)." MICHELET, Jules. La Sorcière, op. cit. p. 295.

${ }^{30}$ Ibid., p. 65.

${ }^{31}$ Ibid., p. 60.

32 "Nul de mes prédécesseurs ne s'en est enquis Ils ne s'informent pas des degrés successifs par lesquels on arrivait à cette chose horrible. Leur Sorcière surgit tout à coup, comme du fond de la terre. Telle n'est pas la nature humaine." Ibid., p. 295.

${ }^{33}$ Ibid., p. 295.
} 
da primeira parte de La Sorcière quer responder, exclusivamente, pelas origens do fenômeno em questáo. Não fugiria demais a esta abordagem informar que a segunda metade do livro, partindo do século XV, é integralmente dedicada à popularização da feitiçaria, registrada tanto pelos manuais de inquisição quanto pelos processos célebres com os quais o historiador encerra essa história. Tampouco seria supérfluo acrescentar que esse segundo livro muda completamente de tom, a diç̧ão lendária sendo substituída por um discurso analítico e bastante razoável, pouquíssimo afeito a narrar artes, satânicas ou não.

Em face do problema assim desenhado, não seria absurdo aproximar a estrutura dessa biografia micheletiana a um procedimento filosófico clássico, qual seja, o da fabricação de uma hipótese narrativa, construída a partir de deduçôes empíricas e visando o estabelecimento de um modelo lógico capaz de responder a questóes que remontam às origens, ou, para falar como Michelet, aos silêncios da história. Vários dos filósofos familiares a Michelet assim procederam e Vico não é exceção: o mito teorético dos bestioni que, aterrados pelo raio, respondem pela origem (segunda) do processo de humanização do homem era mais do que bem conhecido por seu tradutor francês. E assim como para a filosofia, a característica principal do pequeno fio biográfico e dramático micheletiano é seu esforço de razoabilidade, fundado tanto na deduçáo empírica quanto, e em particular, em sua vocação para servir de contraponto crítico ao corpus lendário que, tradicionalmente, visa responder à mesma questáo. "Se a mulher apaixonada, ciumenta e abandonada, se a criança expulsa pela madrasta, se a mãe que apanha de seu filho (velhos temas de lendas), se eles puderam ser tentados, se evocaram o mau Espírito, não são a Feiticeira." ${ }^{34}$

Nesse sentido, o fio fictício parece, de fato, livrar-se da fábula em favor da imaginação dos possíveis, realizando sua vocação crítica: trata-se, antes de tudo, de expor o mais claramente possível um modelo razoável de interpretação do passado, distinto do que chega pelas cadeias fabulosas da tradição.

Nesse capítulo e no seguinte, eu demarquei as situaçôes, os sentimentos, os progressos no desespero que poderiam levar ao tratado enorme do pacto e, o que é bem maior do que o pacto, ao horrível estado da feiticeira. (...) Para facilitar a exposição eu amarrei os detalhes dessa delicada análise a um leve fio fictício. De resto, o enquadramento importa pouco. O essencial é compreender bem que tais coisas não vieram em absoluto (como se procurava fazer crer) da leviandade humana, da inconstância da natureza decaída, das tentações fortuitas da concupiscência. Foi preciso a pressão fatal de uma idade de ferro, aquela das necessidades atrozes; foi preciso que o inferno mesmo parecesse um abrigo, um asilo contra o inferno daqui de baixo. ${ }^{35}$

\footnotetext{
34 "Si la femme amoureuse, jalouse et délaissée, si l'enfant chassé par la belle-mère, si la Mére battue de son fils (vieux sujets de légendes), si elles ont pu être tentées, invoquer le mauvais Esprit, tout cela n'est pas la Sorcière." Ibid., p. 36.

35 "Dans ce chapitre et le suivant, j'ai marque les situations, les sentiments, les progrès dans le désespoir, qui peuvent amener le traité énorme du pacte, et, ce qui est bien plus que le simple pacte, l'horrible état de la sorcière. (...)
} 
A tese da "progressão do desespero" surge, então, como uma tentativa de tornar inteligível, razoável e historiográfico aquilo que, de outro modo, só se explicaria a partir de um dogma de fé ou de uma determinação extrínseca à ação do tempo sobre os homens, extrínseca, portanto, ao conhecimento contingencial típico da história. Em outros termos, tecendo uma biografia cujas datas e fatos marcantes repercutem cuidadosamente àqueles da grande História, o que o pequeno drama da Feiticeira torna explícito é, provavelmente, a recusa de Michelet em pensar o fenômeno da feitiçaria como algo que, incrustado na natureza danada do homem, pudesse ser pensado fora do tempo e fora dos homens concretos que deram cara a esse tempo.

Ora, a bem seguir La Sorcière, esse seria não apenas o pano de fundo da reabilitação da feiticeira antiga como também é a tese principal do historiador ao longo de todo o livro: defender as acusadas de feitiçaria do crime de representarem tão somente uma das faces de uma natureza humana irremediavelmente decaída (do qual, diga-se de passagem, o diagnóstico de histeria, evocado na segunda metade do livro, parece ser apenas um complemento em língua sábia). Contra o dogma do mal natural, de uma humanidade naturalmente corrompida, Michelet alinha males históricos, circunscritos em datas e geografias, em formas de governo, de crença e de valores.

Mas, diferentemente do padrão filosófico e, mais particularmente, dos bestioni viconianos, a biografia na qual Michelet incorpora sua hipótese explicativa implica algo mais, um investimento narrativo e estilístico mais intenso, pari passu a conversão do problema geral (feitiçaria) em problema particular (feiticeira). Ou seja, ele propóe um nível de detalhamento e complexidade que não se coaduna muito facilmente às abstraçóes teoréticas, visto sua decidida ancoragem no corpo e nos afetos da personagem em questão:

Para que a vontade [de fazer o pacto] chegue a este terrível extremo de se vender pela eternidade, é preciso que ela tenha se desesperado. Não é de modo algum o infeliz que chega ao desespero; é o miserável, aquele que tem perfeito conhecimento de sua miséria e que sofre ainda mais por não esperar por qualquer remédio. O miserável, nesse sentido, é o homem do século XIV, o homem de quem se exige o impossível (pagamentos em dinheiro). ${ }^{36}$

\footnotetext{
Pour la facilité de l'exposition, j'ai rattaché les détails de cette délicate analyse à un léger fil fictif. Le cadre importe peu du reste. L'essentiel, c'est de bien comprendre que de telles choses ne vinrent point (comme on tâchait de le faire croire) de la légèreté humaine, de l'inconstance de la nautre déchue, des tentations fortuites de la concupiscence. Il y fallut la pression fatale d'un âge de fer, celle des nécessités atroces; il fallut que l'enfer même parût un abri, un asile, contre l'enfer d'ici-bas." Ibid., p. 78.

36 "Pour que la volonté en vienne à cette extrémité terrible de se vendre pour l'éternité, il faut qu'elle ait désespéré. Ce n'est guère le malheureux qui arrive au désespoir; c'est le misérable, celui qui a connaissance parfaite de sa misère, qui en souffre d'autant plus et n'attend aucun remède. Le misérable, en ce sens, c'est l'homme du quatorzième siècle, l'homme dont on exige l'impossible (des redevances en argent)." Ibid., p. 78.
} 
Ou melhor, a mulher. Mais precisamente, àquela mulher "vestida de verde" que, às vésperas do pacto, é a primeira a pagar o imposto ao senhor. O que a biografia parece entáo ressaltar é mais do que uma hipótese razoável e historicizada de entendimento para as origens do fenômeno, mas, antes, um modo de não perder de vista a dimensão humana do problema. De um lado, essa individuação do enredo ajuda a reforçar a dimensão histórica, ou seja, particular dos eventos narrados, em detrimento de um modelo por demais abstrato de concepçâo do problema: "A cruel história do passado que eu conto aqui não reproduzirá seus dogmas monstruosos, seus sonhos apavorantes. Em bronze, em ferro, estão fixados em seu lugar eterno, na fatalidade do tempo". ${ }^{37}$

De outro lado, porém, a singularidade do ocorrido, redobrada pela individuação biográfica, contrapóe-se, agora, não mais apenas às visagens lendárias da feitiçaria, nem somente ao pensamento dogmático da Igreja, mas também à apreensão generalizante e historicista do fenômeno, inscrita no termo feitiçaria. A recusa a uma abordagem fenomênica do problema, ao acionar o drama biográfico, mira nem tanto no coração da história, mas no coraçáo do historiador e de seus leitores. "Não são sombras e contos" - diz Michelet. E se for assim, a face humana da feitiçaria, inventada por Michelet por meio da biografia da Feiticeira, tanto reativa a vocação prometeica que o historiador imputara à filosofia de Vico, quanto, e, sobretudo, cria uma espécie de armadilha intelectiva, cujo objetivo teria sido o de impedir que esse "assunto terrível, que é pura lágrima e sangue", fosse tomado como puro objeto da imaginação, historiadora ou não.

Ninguém, que eu saiba, viu bem essa história. — Por quê? A imaginação, uma vã poesia misturava, confundia tudo. Este assunto terrível, que é pura lágrima e sangue, divertia. Quanto a mim, tomei-lhe de coração. Deixei de lado as miragens, as fumaças fantasiosas, as neblinas vagas em que os outros se deleitavam. ${ }^{38}$

O passo para "dentro do interior", essa história "tomada de coração" seria, portanto, o movimento que lhe permitiria inscrever, definitivamente, a feiticeira dentro da história, combatendo, com seu corpo interposto, descrições que, privilegiando o campo das ideias — literárias, filosóficas ou fenomênicas —, obliterassem sua face humana e contingencial. Assim, e em todos os níveis aqui analisados, o "pequeno fio biográfico e dramático" propóe uma dinâmica comum, que quanto mais parece se aproximar do domínio do ficcional (mediante a dicção lendária, a narrativa hipotética sobre as origens da feitiçaria ou o drama biográfico), mais desfaz a ficção em proveito da historicidade. Nesse caso, resta, talvez, apenas a pergunta: qual seria mesmo o "pecado" desse historiador?

37 "La cruelle histoire du passé que je raconte ici, ne reproduira pas ses dogmes monstrueux, ses effroyables rêves. En bronze, en fer, ils sont fixés à leur place éternelle dans la fatalité du temps.” Ibid., p. 296.

38 "Personne, que je sache, n'avait bien vu cela. - Pourquoi? L'imagination, une vaine poésie puérile brouillait, confondait tout. On s'amusait à ce sujet terrible qui n'est que larmes, et sang. Moi, je lai pris à cour. J'ai laissé les mirages, les fumées fantastiques, les vagues brouillards où l'on s'y complaisait." Ibid., p. 289. 
Artigo recebido em 23 de julho de 2013 e aceito em 4 de setembro de 2013.

* Doutora em estudos literários pela Universidade Federal de Minas Gerais. Professora adjunta II de língua e literatura francesa na Faculdade de Letras da UFMG. Belo Horizonte, MG, Brasil.

E-mail: juliana.gambogi22@gmail.com. 